\title{
Little millets: Properties, functions and future prospects
}

Shweta Saloni, Sindhu, Sujata, Sushma Kumari and Sandhya Suman

Received : 10.04.2018; Accepted : 13.04.2018

See end of the Paper for authors' affiliation

Correspondence to :

\section{Shweta Saloni} Department of Food Processing and Technology, Bilaspur University, Bilaspur (C.G.) India

Email : shwetasaloni4@gmail. com
- Abstract : In the current scenario where the world around is facing the severe problem of climate change it is greatly impacting the agricultural sector. The farmers have a great problem of irrigation because of depleting water layer. Thus millets which require less water and can easily grow in arid and semi-arid lands. Millets as a whole are highly nutritious, non-glutinous and non-acid forming foods (FAO, 2001). Hence, they are easy to digest. Among all the grains millets are considered to be the least allergenic and most digestible grains. Also millets have low glycemic index. Millets are particularly high in minerals like iron, magnesium, phosphorus and potassium (FAO, 2001). Little millets are good source of proteins, minerals and phytochemicals thus there is a great scope of it in combating nutritional issues and can be helpful in providing adequate nutrition to various sections of the society. Thus in the given review paper a consolidated information regarding little millet is presented.

- Key words : Little millets

- How to cite this paper : Saloni, Shweta, Sindhu, Sujata, Kumari, Sushma and Suman, Sandhya (2018). Little millets: Properties, functions and future prospects. Internat. J. Agric. Engg., 11(Sp. Issue) : 179-181, DOI: 10.15740/HAS/IJAE/11.Sp. Issue/179-181. 